\title{
Tempos anormais e novas fantasias. Novas tendências em direitos humanos, justiça e educação
}

\author{
Carlos Vilar Estêvãoi \\ Universidade do Minho, Portugal
}

\begin{abstract}
Resumo
Depois de caraterizar os tempos atuais como tempos anormais, com a criação, pela ideologia mercantil, de novas fantasias, que prometem o céu na terra em termos de bem-estar, realização pessoal e de justiça, o autor percorre o terreno dos direitos humanos, da justiça, da educação e da escola, no sentido de desocultar novas interpretações, novos mitos, novas anormalidades que estão emergindo no seu interior, congruentes com o metabolismo do mercado, entendido este como metonímia do capitalismo global. Dentro desta visão, os direitos são encarados numa perspetiva de "multiuso", que os torna reorganizáveis a bel-prazer das exigências e das racionalidades dominantes da economia; do mesmo modo, a justiça tende a ser interpretada numa linha individualista e eficientista, ou seja, como um fator que contribui eficientemente para o equilíbrio das trocas comerciais e para a manutenção do equilíbrio da balança social. Por fim, a educação deve constituir-se num subsetor da economia, com uma formatação funcionalista ao serviço das necessidades sociais e económicas originárias do mundo mercantil.
\end{abstract}

Palavras-chave

Mercado; Direitos Humanos; Justiça; Educação

\section{Introdução}

Irei, neste artigo, refletir sobre a ideia de estarmos a viver tempos anormais, não apenas em resultado da complexidade intrínseca e da 
pluridimensionalidade dos conceitos de direitos humanos, justiça e educação, mas também, e sobretudo, por nos colocarem, do ponto de vista normativo, perante valores acondicionados e plastificados, decorrentes quer de uma nova ontologia que define $o$ indivíduo como autorreferencial e simultaneamente como "vida para consumo" (Bauman, 2008), quer de uma nova ideologia congruente com a racionalidade mercantil. Daqui decorrem, entre outras consequências, novas fantasias, que prometem o bem-estar, a realização pessoal, a justiça, o desenvolvimento, enfim, o céu na terra aos crentes desta nova religião chamada mercado.

Assim, num primeiro momento, caraterizarei os tempos atuais e seus fundamentalismos, com destaque para o fundamentalismo de mercado, entendido este como metonímia do capitalismo global. Os impactos do mercado serão, depois, analisados nos seus pontos cegos ao longo de temáticas que, aparentemente, pareceriam mais resguardadas do seu contágio, como é o caso dos direitos humanos, da justiça social e da própria educação. Estes são os propósitos fundamentais deste trabalho, vertidos numa linguagem que, de uma forma por vezes mais militantemente crítica, exprime de modo claro a normatividade assumida pelo autor.

\section{Tempos anormais}

Vivemos numa era de fundamentalismos, não apenas de cariz religioso, que nos prometem outros modos de vida mais puros, mais genuínos, libertando-nos, entre outras vantagens, das perplexidades da escolha. Cada fundamentalismo impõe também a sua autoridade suprema, com anúncios, difundidos por toda a parte, da sua ortodoxia, exigindo aos seus fiéis a condenação de outras autoridades, de outras crenças, de outras práticas, porque ofensivas da verdade transcendente que cada um defende. E um dos fundamentalismos que hoje se destaca é precisamente o do mercado, que, tal como uma religião, apresenta a sua escatologia, as suas verdades (excelência da pós-democracia e o fim da história, por exemplo), os seus profetas, os seus sacerdotes, os seus fiéis, as suas bíblias, os seus lugares sagrados e os seus povos de eleição.

Realmente, aos fundamentalistas da ideologia de mercado pouco thes importa os efeitos nefastos que as suas verdades possam ter na vida e 
dignidade de uma parte da população. Trata-se, afinal, dirão eles, dos efeitos colaterais, dos impactos potencialmente viciosos de um percurso que, em si mesmo, é virtuoso.

Assim, a anormalidade que muitos críticos imputam ao mercado não passa de uma afirmação gratuita, uma vez que os seus procedimentos assentam apenas em outros fundamentos, ou seja, em outras normalidades ou em racionalidades alternativas, todas respeitadoras do sacrossanto princípio da proteção da liberdade de escolha que estrutura a racionalidade mercantil. É esta, aliás, que permite afirmar que, do ponto de vista da eficiência e do bem-estar, os mercados em geral funcionam bem e trazem prosperidade, enquanto que, ao invés, os Estados funcionam mal, criam novas desigualdades e empobrecem os cidadãos.

Além disso, o mercado impõe disciplina, impedindo que os cidadãos, na Ágora política (entendida como espaço de democracia, de ilustração, de voz e de convivência), continuem a viver de modo desregrado, porquanto, amiudadamente, vivem acima das suas possibilidades, alegrados por fantasias difíceis de sustentar. A implementação de políticas de austeridade torna-se assim uma forma quase moral de refrear os instintos desmedidos para o endividamento e de recolocar o indivíduo perante a sua situação de precariedade e de dependência. Obviamente que este desígnio não será para todos, mas apenas para os económica, política e socialmente mais vulneráveis. A estes restará então a vã esperança de um dia ressuscitarem mais prósperos e com as necessidades básicas mais garantidas. Enquanto tal não acontecer, o caminho do calvário terá de ser percorrido pacientemente, como parece ser natural para os que almejam o paraíso.

Esta aparente sensatez do mercado reflete-se numa outra preocupação, quando se defende que só se pode distribuir o que se produz, ou seja, é necessário produzir antes para distribuir depois. Daqui decorre que a questão da justiça não é prioritária, mas sim a riqueza. Na verdade, só quando os celeiros da abundância estiverem cheios é que será possível distribuir o trigo pelos famintos, sem pôr em perigo a ordem social. Isto significa que, num contexto de escassez, a austeridade é uma inevitabilidade mas também uma oportunidade de cada um se tornar, por empenho e mérito próprios, um verdadeiro consumidor, pois é este estatuto a medida de uma vida bem sucedida, da decência e talvez da dignidade humana, que a Ágora, contrariamente ao mercado, parece não dar. 
O que acaba de ser dito expressa uma outra verdade, cruel, sim, mas não para todos. Nesta nova ordem social, nem todos os indivíduos interessam: só os produtores e os consumidores; enfim, os que criam maisvalia é que verdadeiramente contam. Mas há uma outra verdade que não pode ser escamoteada, sobretudo pelos produtores: o emprego é um bem escasso, pelo que terá de ser merecido. Por outras palavras, o desemprego é inevitável e ainda que se tivesse tornado, no Ocidente, numa contagem económica de cadáveres, num apuramento de vítimas não intencionais da luta contra a inflação ou do pagamento da dívida aos bancos do Ocidente (Stiglitz, 2004), nada alterará já este rumo das coisas. Quanto aos consumidores, a sorte estará, hoje mais do que nunca, do seu lado se tiverem possibilidades de obter e manter esse estatuto ou até de ir mais além, investindo numa "vida para consumo" (Bauman, 2008). Para todos, produtores e consumidores, vale no entanto a norma da cidadanização mercantil: a cidadania não passa de um dever de normalidade económica.

Apesar do que ficou dito, ou por isso mesmo, alguns pensam que o clima de mercado agora é mais respirável, que se humanizou e até incorporou muitas críticas de setores mais contestatários. Afirmam, inclusive, que a própria questão da exploração já passou de moda, pelo que as análises de pendor marxista já não se adequam a este "novo espírito do capitalismo atual" (na expressão de Boltanski \& Chiapello, 1999). E acrescentam que, presentemente, os trabalhadores lutam, não tanto contra a exploração de que são vítimas, mas pela oportunidade de serem explorados pelo capital, isto é, pela oportunidade de emprego (Romão, 2004).

Por outro lado, também os pobres de hoje não são mais as pessoas exploradas que produzem o produto excedente a ser, posteriormente, transformado em capital; nem são o exército de reserva da mão de obra à espera de serem integrados no processo de produção de capital, na próxima melhoria económica. Para os defensores da ordem de mercado, eles são, economicamente falando, redundantes, inúteis e não existe nenhuma razão racional para a sua presença contínua (Bauman, 2008), até porque muitos deles nem dívidas têm! Como esclarece este autor, eles não são nem economicamente nem (muitas vezes) fisicamente atraentes e sedutores à nova economia. São os estranhos que a nova sociedade produziu, porquanto cada espécie de sociedade produz a sua própria espécie de estranhos: são 
os que não se encaixam no mapa cognitivo, moral ou estético do mundo intencionado. De certo modo, então, os pobres poluem a alegria e deixam turvo o que tocam e, portanto, o melhor modo de lidar com eles é reconhecerIhes o direito de serem pobres (e de morrerem à fome), dado que o estado de pobreza foi uma opção sua.

No entanto, se quisermos tratar deles, as melhores estratégias serão, por um lado, a incriminação da pobreza, retirando-lhes os direitos ao bemestar, devendo os governos, em alternativa, recanalizar os fundos a eles destinados (por exemplo, para a modernização tecnológica das prisões ou de outros equipamentos punitivos e de vigilância) e, por outro lado, persistir na tónica da brutalização dos pobres (que permaneceriam, apesar de todos os esforços de reabilitação, como indigentes, promíscuos, sujos, preguiçosos, drogados...). Perante este cenário, eles não seriam dignos nem de ajuda, quanto mais de qualquer substancial redistribuição de riqueza (Bauman, 2008, p. 79)! Eles não passam, assim sendo e na linha crítica deste autor, da versão contemporânea da recompensa do pecado.

Aqui chegados, parece que o metabolismo do mercado passa fundamentalmente pela valorização de uma outra sociabilidade, que assenta na ideia de que cada um assuma a responsabilidade de se tornar empresário de si próprio, de que cada um invista, como frequentemente se diz, na sua carteira de competências, de modo a se tornar mais útil, mais empoderado, mais empregável e, por isso, mais vendável.

Mais ainda. Nesta senda da normalização do mercado e do reino do "simulacro", as aparências também contam, pois vivemos numa sociedade de sensações, que tudo espetaculariza, dramatiza e converte em experiência emocional. O espaço emocional é agora, com efeito, o espaço por excelência da convivência e do discurso espontâneo (entretecido por uma linguagem de semelhanças, de assimilações...), substituindo deste modo o espaço do debate racional e da confrontação ideológica.

Daqui decorre, entre outros aspetos, a necessidade e a urgência do aparecer sempre que possível no ecrã público, de cada um constituir a sua rede dita social, de clicar muitos like, ainda que pouco ou nada haja para acrescentar à mensagem recebida a não ser pela postagem ou colagem de uma qualquer informação ou documento descontextualizado e redundante, que momentaneamente nos emocionou. E aqui também vale a regra: os amigos devem ser sobretudo informadores! 
Mas os tempos excessivos que vivemos (e que o mercado propicia e explora) também facilitam esta postura. Como nos diz Augé (2009), é de tal modo avassaladora a superabundância de acontecimentos que nos atropelam e sufocam que parece até não haver lugar para a história, a não ser que esta tenha sido transformada em mais um elemento do espetáculo. A história, com efeito, estreita-se às últimas 48 horas de notícias ao mesmo tempo que se alonga num eterno presente, o que nos deixa apaziguados com a nossa consciência face à avalanche de infortúnios, de acidentes, de catástrofes que desfilam perante nós a cada instante, porque há a certeza de que a seguir virão novos infortúnios, novos acidentes, novas catástrofes, e assim sucessivamente... Não admira, pois, que a nossa consciência moral e social como que flutue e se torne verdadeiramente uma consciência permanentemente transeunte.

Os tempos da atual fase de desenvolvimento económico e financeiro possuem mais esta anormal vantagem: hoje nem é necessário pensar! Vivemos, como nos diz Innerarity (2010), num mundo "em segunda mão", "já interpretado", pois são os meios de comunicação que fornecem a matéria da nossa realidade. Nem precisamos de praticar atos de soberania como, por exemplo, levantar o capô do carro. Agora, somos sobretudo colecionadores de sensações e consumidores de sensações (Innerarity, 2010, p. 189). Consequentemente, o verdadeiro interessa pouco; o que verdadeiramente importa é o big brother, o novo, o conflitual, as quantidades, o local, o escandaloso ou o atual.

Em suma, a justiça que nos faz aparecer é que verdadeiramente conta e que nos confere o direito a ser alguém no espaço público. Trata-se da nova figura da crise ao nível da subjetividade, caraterizada por Hardt e Negri (2012) como o "mediatizado", ao lado do "endividado" (gerado pela hegemonia das finanças e dos bancos), do "assegurado/securitizado" (criado pelo regime de segurança e do estado de exceção generalizado) e do "representado" (criado pela corrupção da democracia, uma vez que esta tende a ser um obstáculo para a sua própria realização).

Finalmente, há a questão do Estado. Ora, devido à sua intrínseca (a)normalidade na lógica do mercado, há que o tornar mais modesto e maneirinho, com a vantagem de, por estes predicados, se tornar mais esbelto. Não é surpreendente, por isso, que os defensores da ordem mercantilista 
profiram o slogan: "o mercado sempre que possível, o Estado sempre que necessário"! Depois, o Estado que se preze deve atuar como o regedor e defensor local do reino do comércio e das finanças extraterritoriais. Ele deve, portanto, criar regras que sustentem os mercados distorcidos no seio dos quais as corporações e os abastados possam explorar os outros.

Quanto ao Estado de bem-estar, considerado um direito do cidadão e uma resposta mais organizada ao problema da pobreza, agora ele está autorizado a funcionar como caridade, que disponibiliza alguns donativos para os mais frágeis, mas que, no fundo, permanece sem justificação face às expetativas do mundo contemporâneo. Aliás, acrescentam os seus críticos, as propaladas virtudes do Estado social muitas vezes não passaram de retórica ou de fantasia porque, em vez de unir pela solidariedade, acabou por separar os cidadãos uns dos outros.

Por outras palavras, o Estado não tem tempo para as pessoas e, por isso, não se deve contar com ele. O Estado relevante deve, antes, proporcionar condições que contribuam para reproduzir a narrativa autoinevitabilista de um futuro orientado para o conhecimento entendido como a verdadeira força de trabalho (Thomson, 2013); ou seja, o Estado deve entrar no romance que é operacionalizado e realizado pelo capital global, cujo enredo fantasista assenta na ideia de que o progresso humano, agora, só é possível ser alcançado por uma economia de conhecimento global.

\section{Direitos humanos em tempos anormais}

Os direitos confrontam-se, hoje, com grandes ambiguidades, que levam alguns a proclamar o seu caráter quase hagiográfico ou então a integrá-los num sistema de ortodoxias ideológicas, enquanto outros preferem salientar sobretudo as suas fragilidades e os discursos contraditórios que sustentam desigualdades e injustiças. De facto, os direitos estão sujeitos, nos dias que correm, a ventos entrecruzados da Ágora e do mercado.

Assim, há teóricos que afirmam que acreditar nos direitos, tais como normalmente são concebidos a partir da Declaração de 1948, é como acreditar em fantasias, em bruxas e unicórnios. São meras ficções, fábulas ou então metanarrativas cujo sucesso se deveu a contingências históricas determinadas, que derrotaram ou inviabilizaram outras igualmente válidas e igualmente promissoras em termos de emancipação (ver Santos, 2013). 
Outros autores, porém, consideram que o discurso que verdadeiramente pode justificar os direitos e a sua universalidade é o dos interesses humanos fundamentais (que têm de ser protegidos e promovidos para se ser humano); ou então - como uma das suas modalidades - o discurso assente no sentimento, na compaixão, na misericórdia, na solidariedade (ver Rorty, 1994), tendo como base a ideia de uma humanidade partilhada assente numa ontologia comum (Turner, 2002); ou, finalmente, o discurso do medo ou da culpa, porque estes nos fornecem também proteção, reduzindo, de certo modo, a nossa exposição ao outro.

Consequentemente, se não estivermos satisfeitos com a fundamentação tradicional dos direitos, é possível defendê-los, nestes tempos duros do mercado, a partir da convicção de que eles atenuam as agruras ou os danos colaterais das medidas mercantis, permitindo ao mesmo tempo ressaltar a bondade natural do homem, que se comove perante a miséria, a pobreza, ou a injustiça que os outros sofrem. Ou seja, não obstante algumas anormalidades, o mercado também se comove e é, por vezes, tão piedoso com os que sofrem como com aqueles que o criticam.

Depois, e em nome do realismo (que pode ser mais ou menos fantasista), o mercado sempre dá uma ajuda à concretização de uma proposta de direitos humanos mais útil, normal e compatível com as exigências do misticismo político e do economicamente correto que comandam a ordem de hoje e que compõem a base espiritual da nossa época. De facto, e do ponto de vista moral, a tirania do economicamente correto faz com que tudo o que economicamente tenha sentido não precise de justificação ou de apoio de um outro sentido, seja ele político, social ou humano. Logo, no caso dos direitos, eles só interessarão verdadeiramente se forem funcionais ou se se constituírem numa espécie de "cavalo de Tróia" a esta nova ordem económica, se ajudarem a demonizar e a criminalizar os adversários ou os proclamados inimigos da humanidade. Se não servirem para tal, os direitos terão de ser reinterpretados e reajustados aos novos valores, onde pontificam, por um lado, o realismo e a ocidentalidade e, por outro, o neoindividualismo e a autorreferencialidade.

É por isso, então, que o conceito "multiuso" dos direitos humanos tem ganhado adeptos. Segundo esta linha, os direitos seriam separáveis, divisíveis, deformáveis, reorganizáveis, a bel-prazer das exigências e das 
racionalidades dominantes da economia. Afirmar, por conseguinte, como na Conferência Mundial sobre os Direitos Humanos, de Viena, realizada em 1993, a indivisibilidade, a interdependência, a inter-relação e a universalidade dos direitos, entre outras caraterísticas, equivaleria a situar-se num plano fantasista que pode aproximar-nos de Deus, mas que nos afasta dos humanos e da plasticidade que as comunidades políticas concretas e os mercados emprestam a esses mesmos direitos.

Depois, os direitos não são iguais ou nem todos merecem o epíteto de direitos, como acontece com os sociais e económicos. Esta pretensão desmedida e anormal de querer ampliar os direitos para além de certos limites não passa de um intento fantasista, quase imperial, de alargar o seu poder a domínios que não lhe pertencem e que, no fundo, os prejudicam.

Daqui decorre que os direitos têm de ser retocados e propostos como relativos e contingentes; eles devem ser, face aos constrangimentos económicos, políticos, sociais ou outros, aquilo que alguns, sobretudo os que ocupam os lugares cimeiros da política, dizem que são, por invocação do que chamam de realismo e sensatez. Mais: eles terão de atender às especificidades políticas e culturais das sociedades. Assim, se as de pendor liberal acentuam os direitos civis e políticos, é compreensível que outras vão por outros caminhos, como é o caso dos novos países emergentes que não podem comprometer-se a respeitá-los porque têm o direito, tal como os mais avançados, ao desenvolvimento económico, à ordem pública e à estabilidade social, o que, em certos contextos, requer regimes políticos mais autoritários, que acentuem as responsabilidades e não tanto as liberdades, que reforcem os deveres e não tanto os direitos.

Consequentemente, os direitos posicionados no interior de uma filosofia idolátrica, a qual, num intento de lucidez e de sistematização, afirma e reafirma princípios e conceitos quase imutáveis e absolutos, indiferentes às vicissitudes históricas e às especificidades culturais dos povos e das gentes, não fazem sentido e podem até contribuir para humilhar o outro, o diferente, o que não satisfaz os padrões estabelecidos.

Em suma, nestes tempos anormais e de algumas fantasias, há que, mais uma vez, ser realista apostando numa abordagem dos direitos assente numa teoria que enfatize, não a condição humana, mas o livre exercício da escolha como a pedra fundacional dos direitos humanos. Ou seja, segundo a 
teoria da escolha, o que verdadeiramente pode justificar os direitos é a promoção e a concretização do exercício da livre escolha (ver Fagan, 2014). Uma leitura possível desta abordagem é que ela pode ser perfeitamente funcional à racionalidade do mercado, que propõe também, ou impõe, uma determinada visão moral de como o mundo deve ser regulado.

Efetivamente, na "economia moral" (expressão de Ball, 2006) do mercado, há apelos a valores, ainda que politicamente despolarizados, que visam adequar-nos a todas as condições e circunstâncias. Na tão apregoada pós-modernidade em que vivemos, correspondente metaforicamente, segundo Harvey (1993), à fase do Espírito Santo, isto é, à fase da volatilidade, podemos tornar-nos em ungidos do mercado, com promessas de sucesso terreno e de felicidade terrenal, se exercitarmos o nosso corpo e a nossa mente nos valores da flexibilidade, da competência, da autonomia, da aprendizagem, da competição...

Uma das ilações que podemos extrair de tudo o que ficou dito é que o terreno dos direitos, ou a busca do seu racional, se constitui, de facto, num campo de encontros e desencontros teóricos, num campo essencialmente contestado (ver Donnelly, 2003; Estêvão, 2012a, 2015) ou contestável, no que respeita concretamente à sua natureza, à sua estrutura, à sua justificação e à sua origem.

Esta vulnerabilidade dos direitos, por mais compreensível que seja em termos teóricos (não apenas pela biologia mas também pela contingência social e histórica dos seres humanos), torna-se, no entanto, particularmente propícia às investidas do mercado e à posição ajoelhada que muitos assumem, como adoradores de novos bezerros de oiro, com outras promessas e outros paraísos. Daí que este balancear entre a lógica da Ágora e a lógica do mercado ao nível dos direitos não deixe de acentuar faticamente alguma (a)normalidade dos próprios direitos e a tendência para se construírem em seu redor algumas fantasias.

\section{Justiça social em termos anormais}

A justiça parece organizar parte significativa do pensamento sociológico, político e filosófico contemporâneo. Na verdade, ela tem fascinado os pensadores do mundo inteiro, desde a civilização greco-latina 
até à atualidade, embora, naturalmente, com perspetivas e acentuações diversificadas.

Deste modo, e no que diz respeito aos nossos tempos, a questão da justiça tornou-se de facto numa questão central no pensamento não apenas jurídico, mas também filosófico, ético-político e sociológico, embora a tonalidade prevalecente em termos do pensamento dominante tenda a ser uma justiça utilitarista, individualista e, por vezes, uma justiça terapeutizada ou refratada por soluções terapêuticas e psicológicas à vulnerabilidade humana e social (ver Ecclestone \& Goodley, 2014). Então, a justiça social originária, de radical mais crítico, deixou de ter que ver com redistribuição ou com o processo de implicação e responsabilização social que reafirma a nossa ligação e nos move como um coletivo solidário, passando a apresentarse simplesmente como justiça, sem qualquer adjetivação, mas sempre pronta a assumir novas intencionalidades (até porque, como Hayek - um dos expoentes do pensamento neoliberal - defendera já, a "expressão 'justiça social' não pertence à categoria do erro, mas à do absurdo" [1985, p. 98]).

Uma outra perspetiva, congruente com a racionalidade de mercado, vê a justiça como um dos fatores que contribui eficientemente para o equilíbrio das trocas comerciais e para a manutenção do equilíbrio da balança social que a mulher de olhos vendados (representação habitual da justiça legal) sempre ostenta, assegurando, talvez não por excesso de visão, mas antes por excesso de cegueira, o princípio de dar a cada um o que lhe pertence ou o que é merecido.

Uma outra conceção de justiça fiel à (a)normalidade dos mercados é a que sanciona a ideia de que tudo se justifica desde que cada um retire o máximo proveito, a máxima felicidade ou o máximo de vantagens das situações criadas (ver Sandel, 2011). Ou, por palavras mais simples: o que é justo é o que se vende bem. $E$ isto tanto serve para bens e serviços como para pessoas. Ser vendável então, por exemplo pelas competências adquiridas, torna-nos potencialmente mais justos, mais ajustados, mais portáteis, mais merecedores de nos sentarmos à mesa do rei-mercado e de participarmos das celebrações em sua honra.

Uma sociedade consumista (congruente com as preocupações do mercado e caraterizada por julgar e avaliar os seus membros pelas capacidades e conduta relacionadas com o consumo; ver Bauman, 2009) dá- 
nos uma ajuda milagrosa para termos uma mente e um corpo a condizer com os requisitos da nova justiça de mercado. Se, por artes confessadas ou inconfessáveis, a nossa mente e o nosso corpo se mantiverem ajustados, ou pelo menos não defeituosos, as hipóteses de sermos justamente recompensados por novas ofertas de trabalho, por novas oportunidades de exibição de atributos ou de estarmos na boca de cena da atualidade serão maiores, dando-nos simultaneamente a oportunidade de alardear a nossa virtude (fantasiada) como consumidores exemplares.

De certo modo, então, para se poder ser alguém neste tipo de sociedade, para se ter um tratamento justo e merecido neste tipo de sociedade, há que estar in, em upgrade constante, que impeça a nossa remoção para o caixote do lixo, ou seja, para a inutilidade pública económica. Mais: há que ter a capacidade de renascer em cada produto (ou até de cada um se transformar em mercadoria)... E se, de vez em quando, nos lembrarmos dos outros, com manifestações públicas de donativos, a própria justiça pode transformar-se num festim: isso ajudará a aplacar a consciência moral e a suportar a ausência de justiça durante os dias úteis, segundo Bauman (2009, p. 88). Em suma, independentemente das nossas considerações sobre justiça, nas sociedades ditas mais evoluídas, o bom funcionamento dos mercados depende também desta variável, uma vez que a justiça o torna mais transparente, mais gerível, mais eficiente, mais predizível, para além de tornar as sociedades mais decentes e (pós)humanas.

Depois, e no plano mais estritamente político, a justiça continua, também, a necessitar do Estado, porque desta relação ambos beneficiam. Todavia, é sabido que os dois vivem frequentemente em pecado, tal o grau de promiscuidade que experienciam e o grau de injustiças que encobrem. Não admira, por isso, que, na lógica de um Estado-Mercado, por exemplo, a justiça perca naturalmente o seu adereço "social", tornando-se perfeitamente funcional à colonização do mundo de vida pelo poder e pela economia. Por sua vez, acobertado pela justiça, aquele mesmo Estado pode proteger, por exemplo, determinadas áreas de maior predileção (como a financeira) e mobilizar processos pouco consentâneos com a procura do bem comum.

Mas dir-se-á que a justiça separada do Estado ou não confinada às fronteiras nacionais precisas torna-se numa inutilidade. Por outras palavras, a justiça, para ser eficiente e útil, é sempre contextual e territorializada, e, além 
disso, pertence aos cidadãos e não propriamente às pessoas. Uma das muitas consequências que daqui resulta, muito apreciada pelos mercados, é que não há propriamente culpa nem responsabilidade política pelo que acontece fora das fronteiras em termos de injustiças ou de não respeito pelos direitos, mesmo que objetivamente as práticas protecionistas estatais ou de índole económico-financeira prejudiquem outros povos.

Dentro desta lógica territorializada, de não compromisso, por exemplo o "modelo de conexão social" de Young (2011) - que significa que "todos os que contribuem com os seus atos para os processos estruturais que provocam alguma consequência injusta compartem a responsabilidade dessa injustiça" (p. 108) - não faz qualquer sentido. Na verdade, uma vez que as fronteiras territoriais se tornam de certo modo as fronteiras morais dos nossos deveres, dos nossos julgamentos e dos nossos empenhamentos sociais, tudo o que for para além destes limites não obriga ninguém, nem ninguém deverá ser responsabilizado por eventuais danos ou malefícios infligidos aos outros ou a outros povos.

Face ao que ficou dito, ganha sentido afirmar então que, nestes tempos anormais em termos de estruturação e priorização de valores, a justiça também se tornou anormal. Com efeito, se é verdade que, ao implicar várias dimensões (redistribuição, reconhecimento, representação), vários sujeitos de justiça (local, regional, global) e vários critérios para resolver ou decidir as disputas (critérios democráticos, populistas, hegemónicos), a justiça se tornou teoricamente anormal, tal como defende Fraser (2013), é igualmente verdade que, do ponto de vista normativo, ela também não escapou a esta mesma anormalidade, trivializando-se ou tornando-se particularmente sombria.

Coerentemente, segundo a racionalidade de mercado, a justiça como redistribuição está desatualizada, porque os tempos hodiernos são sobretudo de justiça como reconhecimento (e, com efeito, esta é uma dimensão também importante da justiça; ver Fraser \& Honneth, 2005). Então, o mercado brilha de justiça, porque, mais do que o Estado social, dá atenção às diferenças culturais, para que os indivíduos continuem... como diferentes. Se estas diferenças emergem sempre ligadas a uma determinada estrutura económica ou a outros antagonismos relacionados com a ordem de status da sociedade (interseccionalizadas com a classe, etnia, género, idade...) no próprio seio das 
comunidades particulares, pouco interessa, tal como pouco importa se as diferenças em questão apenas servem para acentuar, ocultando, a inferioridade ou a subordinação (Fraser, 1997; Casa-Nova, 2013, 2014).

Mais. Se, nos tempos atuais, a justiça social, do ponto de vista redistributivo ou económico (nomeadamente como justa distribuição dos recursos materiais), pouco importa, a justiça política é de igual modo de pouca valia. E porquê? Porque, num tempo de misticismo mercantil, uma das estratégias utilizadas para persistir na ampliação e na consolidação das suas fantasias e para penetrar mais facilmente em áreas tradicionalmente pouco ou nada exploradas é precisamente a despolitização da vida pública e o esbatimento das tensões sociopolíticas, pela via da harmonização de interesses e da fantasia do consenso. Coerentemente, então, entender a justiça como eliminação da dominação e da opressão institucionalizadas, ao nível da tomada de decisão ou do poder, da divisão do trabalho e da cultura, na linha proposta por Young (1990), parece ecoar como a voz subterrânea de tempos idos, quiçá do período jurássico, que nos amedronta só de pensar no seu regresso.

Concluindo: trilhar o íngreme caminho da justiça social nestes tempos anormais, de mal-estar, de predomínio do mercado, não é tarefa fácil, a não ser que a justiça se descolore e se privatize e se torne, ela própria, uma fantasia necessária de grande serventia para uns poucos e quase dispensável para os restantes.

\section{A melhor educação em tempos anormais}

A educação vive, ou sobrevive, hoje num atoleiro de ideias hegemónicas, como nos diz Clarke (2012, p. 307) quando refere: que o mercado exige o aumento da produtividade como o último desígnio educacional e social; ou que a prestação de contas, mais do que a confiança, deve ser a chave da excelência educacional; ou que esta, realizada através de combinação de mecanismos de prestação de contas gerencialista e por noções de escolha orientadas pelo mercado, é compatível com a equidade; ou que a mesma prestação de contas é um assunto de eficiência técnica e não uma escolha normativa; ou, finalmente, que a escolha e a diversidade são as chaves da justiça social, recusando a possibilidade de algumas diferenças 
poderem estar ligadas às desigualdades sistémicas e às desvantagens estruturais. Ainda no dizer do mesmo autor, a ausência da política também nas políticas educacionais neoliberais é o que carateriza verdadeiramente os nossos tempos anormais, propiciando as medidas de mercantilização, privatização, padronização e prestação de contas em muitos sistemas educativos.

Na verdade, constata-se hoje (e sem questionar o processo referido de despolitização) uma acentuação contraditória ao nível das políticas para a educação e a formação: por um lado, defendem-se as políticas desregulatórias face ao papel demasiadamente interventor do Estado, mas, por outro, enfatizam-se as orientações de regulação (pretensamente apolíticas) favoráveis ao mercado e que passam pela valorização, no seu grau máximo, dos procedimentos, entre outros, de mensurabilidade e de comparabilidade internacional a que devem subordinar-se os sistemas educativos e formativos de qualidade. Complementarmente, ou por isso mesmo, perdura também na educação o debate em torno dos limites e da definição do que deve entender-se por espaço público e de qual deve ser o lugar da escola pública nesse mesmo espaço. Ainda que muitos proponham a complementaridade entre o público e o privado ou a criação de redes de interconexão entre eles, outros há que veem esta conciliação como um artifício para a invasão e re-hegemonização do privado face ao público, para, deste modo, fazer vingar na educação a narrativa da agenda neoliberal ou da agenda da transformação sob o signo do livre mercado.

Indiferentes, pelo menos aparentemente, a estas polémicas consideradas quase ociosas, têm surgido na educação iniciativas de pendor empresarial, como é o caso de escolas concebidas como redentoras da educação e da formação de qualidade e mais adaptáveis ao espírito dos nossos tempos, à economia do conhecimento e à lógica de mercado, porque se apetrecharam mais adequadamente para vender um produto, ou melhor, um privilégio (porque nem todos o podem adquirir). Além disso, elas têm o apoio de outras organizações que podem produzir mais rapidamente e com rigor kits educativos e formativos facilmente manejáveis, obedecendo inclusive a uma pedagogia pronta-a-servir, que dispensa os seus profissionais até de pensar! 
Neste ambiente, encaixam-se perfeitamente bem as "ideologias de conveniência" ou as ideologias fashion, como as da qualidade, das competências, da auditoria, da avaliação, da certificação, da aprendizagem ao longo da vida. Para além de revelarem um fino trato com os requisitos da competitividade e da produtividade, ou com a narrativa mais ampla do progresso através da economia do conhecimento global, estas ideologias exalam um perfume inebriante pós-moderno, um sex-appeal de top models, que nos incapacitam, tal o seu encanto delirante, de as rejeitar ou até de emitir um juízo menos favorável! $E$ haverá uma outra vantagem: enquanto ocuparem o espaço da preocupação dos políticos e dos educadores, elas tornarão grandes e bem cheirosos os seus seguidores.

E há ainda a grande ideologia da igualdade de oportunidades (figura cardinal da justiça escolar, embora não passe de uma das suas formas, uma vez que pode ser entendida, por exemplo, como igualdade de oportunidades meritocrática, igualitária, compensatória ou liberdade natural), que estrutura os sistemas sociais e educativos das sociedades liberais democráticas e que as torna imbatíveis em termos de equidade e, aparentemente, de justiça social (ver, a este propósito, Estêvão, 2001)! O princípio de igualdade de oportunidades é, na verdade, necessário porque mobiliza vários princípios de justiça (e postulados morais) numa sociedade democrática, concitando adesões provenientes de setores ideologicamente desencontrados. E tanto é assim que, por exemplo, e como afirma um declarado defensor do mercado, até "a reivindicação de igualdade de oportunidade, ou de iguais condições iniciais, atrai muitos que, em geral são favoráveis ao sistema de livre mercado, tendo sido por eles apoiada" (Hayek, 1985, p. 105). Ou seja, grande sortilégio possui este princípio para merecer tão grande consenso até de setores porventura inesperados! Perante tamanho consenso, talvez se justifique que a melhor educação dos tempos anormais deva continuar a passar obrigatoriamente por este ponto nodal da ideologia educativa, porque alicerçado também numa certa ideia de justiça entendida sobretudo como equidade.

Então, este critério da equidade, se compreendido como justiça na distribuição de inputs de escolarização ou de acordo com a ideia de cada um receber segundo a sua contribuição, pode revelar-se muito útil para incutir uma racionalidade particularmente competitiva, meritocrática, coerente com 
um certo privatismo e individualismo (Estêvão, 2002, p. 131) tão acarinhados pelo mundo mercantil. Como consequências deste modo de ver a narrativa da equidade (reconhecendo, no entanto, que há outras formas de a compreender não coincidentes com a perspetiva aqui exposta, como, por exemplo, a de Rawls, 1993; ver Bolívar, 2005), temos, por exemplo: a valorização dos resultados em detrimento dos processos e propósitos (intenções); a acentuação de que a aprendizagem ocorre do mesmo modo incremental para todos; a mensuração da aprendizagem; a exigência de que o conhecimento, as disposições e as capacidades se tornem em algo a ser processado, gerido, parcelado (ver Thomson, 2013)... Assim sendo, nada impede de afirmar que a justiça como equidade em educação poderá ser satisfeita perfeitamente bem seguindo os ditames do mercado. Este mercado na educação poderia até cumprir melhor a missão da justiça, removendo, por exemplo, os constrangimentos das famílias no acesso a resultados e oportunidades; aumentando, pela competição por alunos, a eficiência (seletiva); permitindo às famílias escolherem a escola que melhor satisfizesse as necessidades educativas; dando aos bons alunos oportunidades para serem ainda melhores; tornando legítimas as desigualdades educativas e sociais porque resultantes da competição escolar.

Num outro plano, são também cada vez mais as vozes que defendem que a própria escola está a transmutar-se num "lugar de vários mundos" (Estêvão, 2004), de várias justiças, de vários direitos, de vários públicos, pelo que a visão mais tradicional que a encarava como uma instituição, com uma função socializadora e integradora claras das camadas mais jovens pelos valores dos adultos, já não se adequa à nova ambição da escola. Esta deixou de ser, por conseguinte, um templo onde se celebrava a "missa escolar" (expressão de Dubet) para gente devota e devotada. Ela dessacralizou-se e é antes, e cada vez mais, um espaço de cruzamento de várias racionalidades, de vários princípios de justiça, onde se inclui, naturalmente, a lógica mercantil.

Então, esta exposição da escola à pluridimensionalidade, à presença de esferas de justiça no seu interior, coloca-a perante desafios nem sempre fáceis de serem contornados no que respeita à normatividade a seguir e à legitimidade a defender; além disso, levanta dificuldades relacionadas com a sua governação, dado que pode propiciar formas marcadamente gerencialistas, fiéis ao receituário do new public management para todas as 
estações; esta multidimensionalidade pode, ainda, conduzir à compreensão da escola como escola light, onde tudo é possível, inclusive conviverem pessoas e utopias vazias, ou valores contrastantes que acentuam a justiça do individualismo e da competição, mas também graus variados de confiança e colaboração (ver Woods \& Bagley, 1996), embora de fraca intensidade.

Mas se vivemos num tempo com uma tendência crescente para uma menor capacidade de pensar e de argumentar e a favor de uma formatação funcionalista pelas necessidades sociais e económicas originárias do mundo mercantil (nomeadamente, e de forma mais clara, no ensino superior), não surpreenderá que a racionalidade dos mundos empresarial e mercantil venha a exercer o seu fascínio e influência na conceção e condução das organizações educativas, na conceção e gestão dos currículos, entre outros aspetos, inebriando alguns espíritos mais propensos à aceitação sem discussão das modas educativas e das suas insidiosas ideologias de conveniência. E de tal modo poderá ser cativante esta racionalidade que mesmo o êxito ou o fracasso escolar e social poderão ser privatizados, remetidos para a área das opções individuais.

Malgrado as suas consequências pouco consentâneas com a natureza e metas da educação, esta tendência privatista tem vindo a impor-se cada vez mais em nome de uma melhor educação. E se tradicionalmente os sistemas educativos e as suas organizações (designadamente as escolares) eram locais protegidos por discursos de bem comum, de serviço público, hoje, pela necessidade de transformar a educação num bem posicional privatizado, num setor de serviço crucial para o crescimento e prosperidade da economia (ver Estêvão, 2006, 2012b), eles tornaram-se em mecanismos a favor de lógicas apátridas, que vêm corrompendo a sua verdadeira missão, em nome, contraditoriamente, de uma boa educação, mais adequada e mais ajustada à formação do capital humano, ao perfil nómada, autorreferencial, do homem de hoje, que se confronta cada vez mais com o desafio de pensar apenas em si próprio... Por isso, renovam-se os apelos para uma inversão desta tendência no sentido de a educação se estruturar na preocupação da justiça social e da emancipação individual, reconhecendo-se simultaneamente que, não raramente, o discurso educacional da justiça social, vinculado até pela pedagogia crítica, tem corrido o risco de reforçar os pressupostos do individualismo, da competição, do consumismo, que ajudam a reproduzir a atual economia política injusta. 
Combater as fantasias do mercado e os seus efeitos sociais e educativos será então um objetivo que deverá presidir à educação crítica de hoje, deixando de ser uma espécie de Cinderela dos tempos anormais, com o pé sempre pronto a ajustar-se às medidas do sapato, ajudada pelas magias da fada-madrinha do mercado. $E$ isto exige, desde logo, que a escola não se confine a ser um simples palco para representações estranhas à sua alma e aposte antes numa alternativa que exercite as razões e os afetos, a racionalidade e a razoabilidade, a justiça e o cuidado, o conhecimento e o reconhecimento, a crítica e a solidariedade, o saber e a sabedoria.

\section{Concluindo..}

Segundo a nova ortodoxia global, a constelação discursiva dos nossos tempos está crescentemente redefinindo os domínios de validade, normatividade e atualidade, quer da democracia, quer dos direitos, quer da justiça, quer da própria educação, de acordo com o racional económico dominante. $O$ resultado de tudo isto é que prevalece agora uma compreensão mínima de direitos e de justiça social, evacuando-se, ou marginalizando-se, consequentemente, as políticas e as práticas enformadas por abordagens substantivas de direitos e de justiça social, a favor das caraterísticas políticas e sociais dos mercados que enquadram e enformam as ações dos indivíduos, dos grupos e das organizações.

Do mesmo modo, a educação tende a apresentar-se, nos dias que correm, como um subsetor da economia, como uma das melhores estratégias para o incremento da competitividade, em que o cidadão que conta é o que pode transformar-se em cliente ou em consumidor (e a mecânica supraindividual do mercado sabe identificar, e determinar, bem os seus clientes ou consumidores preferenciais). No mesmo sentido, as escolas que melhor servem este figurino são as mcEscolas (Estêvão, 2004), com suas pedagogias prontas-a-servir para estudantes, que devem ser encarados sobretudo como aprendentes e um pouco como cidadãos. Por conseguinte, há que adequar os seus corpos e as suas mentes a tais desígnios para não serem excluídos deste processo histórico e dos imperativos da "pósdemocracia" (Crouch, 2004). 
Em contracorrente a este cenário e à tentativa de traduzir tudo o que é de importância social como questão privada, há que revalorizar os direitos que nos fazem existir como humanos com dignidade; a justiça social que nos dá o sentido do nosso lugar e o sentido do lugar do Outro; e a educação que nos ajuda, mesmo pelo seu utopismo, a encontrar um lugar de esperança, pois se há, neste mundo anormal e de rendição, tantas vias para nos tornarmos cruéis, deverá haver pelo menos uma para nos tornarmos mais humanos, mais justos, mais educados. $\mathrm{E}$ tudo isto exige mais política, obviamente...

\section{Referências}

Augé, M. (2009). Non-places. An introduction to supermodernity. London: Verso.

Ball, S. (2006). Sociologia das políticas educacionais e pesquisa crítico-social: Uma revisão pessoal das políticas educacionais e da pesquisa em política educacional. Currículo sem Fronteiras, 6(2), 10-32.

Bauman, Z. (2008). Vida para consumo. Rio de Janeiro: Zahar Editor.

Bauman, Z. (2009). Vida líquida. Rio de Janeiro: Zahar Editor.

Bolívar, A. (2005). Equidad educativa y teorías de la justicia. REICE - Revista Electrónica Iberoamericana sobre Calidad, Eficacia \& Cambio en Educación, 3(2), 42-69.

Boltanski, L., \& Chiapello, E. (1999). Le nouvel esprit du capitalisme. Paris: PUF.

Casa-Nova, M. J. (2013). Direitos Humanos: Da sua possibilidade teórica à sua (im)possibilidade prática numa era de naturalização das desigualdades. Revista Portuguesa de Educação, 26(2), 43-44.

Casa-Nova, M. J. (2014). Thinking about difference: Some notes on the role of social scientists as transformative intellectuals. In G. Finger (Ed.), Roma rights and discrimination (pp.142-151). Oldenburg: Paulo Freire Verlag.

Clarke, M. (2012). The (absent) politics of neo-liberal education policy. Critical Studies in Education, 53(3), 279-310.

Crouch, C. (2004). La posdemocracia. Madrid: Taurus.

Donnelly, J. (2003). Universal human rights in theory and practice. New York: Cornell University Press.

Ecclestone, K., \& Goodley, D. (2014). Political and educational springboard or straitjacket? Theorising post/human subjects in an age of vulnerability. Discourse: Studies in the Cultural Politics of Education, 1-14. doi: 10.1080/01596306.2014.927112

Estêvão, C. V. (2001). Justiça e educação. S. Paulo: Cortez Editora.

Estêvão, C. V. (2002). Justiça e educação. Uma reflexão sobre a dialectologia da justiça em educação. Revista Crítica de Ciências Sociais, 64, 107-134. 
Estêvão, C. V. (2004). Educação, justiça e democracia. S. Paulo: Cortez Editora.

Estêvão, C. V. (2006). Educação, justiça e direitos humanos. Educação e Pesquisa, 32(1), 85-101.

Estêvão, C. V. (2012a). Direitos humanos, justiça e educação na era dos mercados. Porto: Porto Editora.

Estêvão, C. V. (2012b). Políticas e valores em educação. Repensar a educação e a escola como um bem público. Vila Nova de Famalicão: Húmus.

Estêvão, C. V. (2015). Direitos humanos, justiça e educação. Uma análise crítica das suas relações complexas em tempos anormais. ljuí: Editora Unijuí.

Fagan, A. (2014). Philosophical foundations of human rights. In T. Cushman (Ed.), Handbook of human rights (pp. 9-22). London: Routledge.

Fraser, N. (1997). Justice interruptus: Critical reflections on the 'postsocialist' condition. New York: Routledge.

Fraser, N. (2013). Justiça anormal. Revista da Faculdade de Direito da Universidade de S. Paulo, 108, 739-768.

Fraser. N., \& Honneth, A. (2005). Redistribución o reconocimiento?. Madrid: Morata.

Hardt, M., \& Negri, A. (2012). Declaración. Madrid: Ediciones Akal.

Harvey, D. (1993). A condição pós-moderna. S. Paulo: Loyola.

Hayek, F. (1985). Direito, legislação e liberdade: Uma nova formulação dos princípios liberais de justiça e economia política - Vol. II: A miragem da justiça social. São Paulo: Visão.

Innerarity, D. (2010). O novo espaço público. Lisboa: Editorial Teorema.

Rawls, J. (1993). Uma teoria da justiça. Lisboa: Presença.

Romão, J. E. (2004). Prefácio. In S. Stoer, A. Magalhães, \& D. Rodrigues, Os lugares da exclusão social: Um dispositivo de diferenciação pedagógica (pp. 5-12). S. Paulo: Cortez.

Rorty, R. (1994). Contingência, ironia e solidariedade. Lisboa: Ed. Presença.

Sandel, M. (2011). Justiça. O que é fazer a coisa certa. Rio de Janeiro: Civilização Brasileira.

Santos, B. S. (2013). Se Deus fosse um ativista dos direitos humanos. S. Paulo: Cortez Editora.

Stiglitz, J. (2004). Globalização - A grande desilusão. Lisboa: Terramar.

Thomson, P. (2013). Romancing the market: Narrativising equity in globalizing times. Discourse: Studies in the Cultural Politics of Education, 34(2), 170-184.

Turner, B. (2002). The problem of cultural relativism for the sociology of human rights: Weber, Schmitt and Strauss. Journal of Human Rights, 1(4), 587-605.

Woods, P., \& Bagley, C. (1996). Market elements in a public service: An analytical model for studying educational policy. Journal of Education Policy, 11(6), 641-653.

Young, I. (1990). Justice and the politics of difference. Princeton: Princeton University Press.

Young, I. (2011). Responsabilidad por la justicia. Madrid: Morata. 
ABNORMAL TIMES AND NEW FANTASIES. NEW TRENDS IN HUMAN RIGHTS, JUSTICE AND EDUCATION

Abstract

After characterizing the current times as abnormal times, with the creation, by the ideology of the market, of new fantasies that promise heaven on earth in terms of well-being, personal fulfillment and justice, the author makes an incursion in the land of human rights, justice, education and school, in order to unveil new interpretations, new myths, new abnormalities that are emerging within it, congruent with the market, understood as metonymy of global capitalism. In this view, rights are seen from a "multiuse" perspective, which makes them "malleable" at will and at the demands of the dominant rationality of the economy; likewise, justice tends to be construed from an individualistic and efficiency perspective, that is, as a factor that effectively contributes to the balance of trade and for maintaining the evenness of the social balance. Finally, education should constitute a sub-sector of the economy, with a functionalist format at the service of social and economic needs that come from the mercantile world.

Keywords

Market; Human Rights; Justice; Education

TEMPS ANORMAUX ET NOUVELLES FANTAISIES. LES NOUVELLES TENDANCES EN MATIÈRE DE DROITS HUMAINS, DE LA JUSTICE ET DE L'ÉDUCATION

\section{Résumé}

Après avoir caractérisé les temps actuels comme anormaux, avec la création, à travers de lidéologie mercantile, de nouvelles fantaisies qui promettent le ciel sur terre du point de vue du bien-être, de la réalisation personnelle et de la justice, l'auteur fait le tour sur les droits de l'homme, la justice, l'éducation et 
l'école à fin de mettre à jour de nouvelles interprétations, de nouveaux mythes, de nouvelles anormalités qui y surgissent, compatibles avec le métabolisme du marché, compris comme une métonymie du capitalisme global. Selon ce point de vue, les droits sont considérés dans une perspective de "multifonction", qui les rend réorganisables au beau plaisir des exigences et des pensées dominantes de l'économie; de la même façon, la justice a tendance à être interprétée sous une philosophie individualiste et d'efficacité, c'est à dire, comme un facteur qui contribue efficacement à l'équilibre des échanges commerciaux et à la manutention de l'équilibre de la balance sociale; finalement, l'éducation doit s'assumer comme un sous-secteur de l'économie, avec une formatation fonctionnelle au service des besoins sociaux et économiques originaires du monde mercantile.

Mots-clé

Marché; Droits humains; Justice; Éducation

Recebido em abril/2015 Aceite para publicação em julho/2015

i Professor aposentado, Instituto de Educação, Universidade do Minho, Portugal

Toda a correspondência relativa a este artigo deve ser enviada para: Carlos Vilar Estêvão, Instituto de Educação, Universidade do Minho, Campus de Gualtar, 4710-057 Braga. E-mail: cestevao@ie.uminho.pt. 